\title{
Advanced Robotic Surgery: Liver, Pancreas, and Esophagus - The State of the Art?
}

\author{
Pasquale Scognamiglio Björn-Ole Stüben Asmus Heumann Jun Li \\ Jakob R. Izbicki Daniel Perez Matthias Reeh \\ Department of General, Visceral and Thoracic Surgery, University Hospital Hamburg-Eppendorf, Hamburg, Germany
}

\section{Keywords}

Robotic surgery · Pancreas · Esophagus · Liver · Minimally invasive surgery

\begin{abstract}
Background: The trend in performing robotic-assisted operations in visceral surgery has been increasing in the last decade, also reaching the challenging field of hepatic, pancreatic, and esophageal surgery. Nevertheless, solid data about advantages and disadvantages of the robotic approach are still missing. The aim of this review is to analyze the benefit and impact of robotic surgery in the field of hepatic, pancreatic, and esophageal surgery, focusing on the comparison with the conventional laparoscopic or open approach. Summary: The well-known advantages of laparoscopic surgery in comparison to the open approach are also valid for robotic surgery, with the addition of a 3D-view camera, wristed instrumentation, and an ergonomic console. On the other hand, the use of a robotic system leads to longer operating time and higher costs. Randomized controlled trials comparing the robotic approach with the laparoscopic one are still missing. Key Message: Recent meta-analyses show promising results of the usage of robotic systems in advanced surgical procedures, like hepatic, pancreatic, and esophageal resections. Further randomized studies are needed to validate the postulated benefit.
\end{abstract}

() 2021 S. Karger AG, Basel

P.S. and B.-O.S. contributed equally and share first authorship.

\section{Introduction}

Since the first appearance of the Arthrobot in the operating theater in 1985 [1], the role of the robot has increasingly gained importance in the assistance to surgical procedures, with the da Vinci Surgical System one of the most important surgical innovations over the last decade $[2,3]$. In addition to the well-known advantages of laparoscopic surgery over open surgery, such as better site visualization, shorter hospital stay, less postoperative pain, and less wound-related complications, robotic surgery (RS) offers: (1) a stable 3-dimensional view with the possibility to zoom in; (2) wristed instrumentation with a higher grade of mobility than human hands and a better filtration of tremor than laparoscopic instruments; and (3) an ergonomic surgeon console, which results in reduced backache for the surgeon. On the other hand, the use of the robot leads to worse haptics, higher costs, and longer operating time than laparoscopy [4-6]. In particular, with regard to costs, robotic surgical systems have high fixed costs (from USD 1 million to USD 2.5 million per unit) with the addition of costly maintenance and the use of single-use robotic appliances [7].

The main evolution of RS took place in the field of urology, in particular for prostatectomies [8]. Its establishment in general surgery was slower, but nowadays, robotic-assisted operations are being safely performed in all surgical sites [9].

The aim of this review is to describe and critically analyze the use of RS in the field of hepatic, pancreatic, and esophageal surgery. A comprehensive search of electron- 


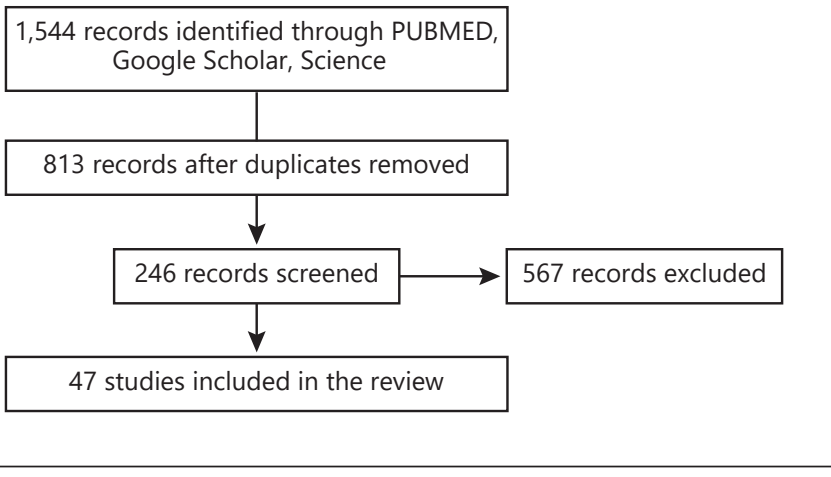

Fig. 1. Flow diagram of study selection.

ic databases (PubMed, ScienceDirect, and Google Scholar) using the keywords "robot," "surgery," "esophagus," "liver," and "pancreas" was performed. The referencelists provided by the identified articles were additionally handsearched for additional studies missed by the search strategy, and this method of cross-referencing was continued until no further relevant publications were identified. Priority was given to randomized controlled trials, metaanalysis, and retrospective studies on large cohorts of patients. Our flowchart is summarized in Figure 1. Evidence from these data was critically analyzed and summarized to produce this article. The studies were subject to significant bias, in terms of both the selection criteria for the study participants and also the reporting of data.

\section{Robotic-Assisted Liver Surgery}

The first report of robotic surgical techniques used for a liver segment resection was in 2003 by Giulianotti et al. [10]. Initially, benign lesions with small diameters in peripheral liver segments were resected robotically $[11,12]$.

Since then, surgical indications for robotic liver resections have been gradually expanding. To date, hemihepatectomy and extended hemihepatectomy are being performed safely [13]. Liver donor hepatectomy and even associating liver partition with portal vein ligation have been performed robotically $[14,15]$.

Whereas the known advantages of the minimally invasive technique over open liver surgery (OLS) seem to be confirmed for the robotic-assisted liver surgery (RLS), the evidence of possible advantages and disadvantages compared to laparoscopic liver surgery (LLS) is still poor and is mainly based on case reports or retrospective studies with small patient cohort $[16,17]$. Moreover, the length of the included liver resections often varies from minor (e.g., for benign tumors or single metastases) to major hepatectomies, resulting often in biased results.
In a recently published meta-analysis from Ziogas et al. [18], RLS was shown to be equivalent to LLS for major hepatectomies in terms of complications, mortality, conversion to open surgery, operating time, blood loss, oncological radicality, and length of stay. Differently, in a previous meta-analysis from Qiu et al. [19] including every type of liver surgery, RLS showed a longer operating time than LLS (see Table 1). Significantly lower 45-day readmission rate and complication rate were reported for RLS than both LLS and OS in a comprehensive analysis of the nationwide readmission database of the USA from Aziz et al. [20].

One of the main limitations of RLS is the lack of haptic feedback. The use of the fluorescent dye indocyanine green was shown to partially solve this problem by accumulating in hepatocellular cancers and around liver metastases. The near-infrared camera integrated in the $\mathrm{Da}$ Vinci ${ }^{\circledR}$ System allows detecting the accumulation and leads therefore to a higher rate of $\mathrm{R} 0$ resections [21].

In regard to the costs, reported data are conflicting. In a study by Sham et al. [22], perioperative costs were higher in robotic hepatectomy than in open procedures. When considering the lower postoperative costs by shorter postoperative stay, robotic hepatectomy was shown to produce lower overall costs. In contrast, Xu et al. [23] compared hepatectomy for hilar cholangiocarcinoma and found the overall costs of RS to be higher than those of open hepatectomy.

\section{Robotic-Assisted Pancreas Surgery}

\section{Robotic-Assisted Pancreaticoduodenectomy}

Pancreaticoduodenectomy (PD) is still considered one of the most challenging surgical procedures also for experienced visceral surgeons. Minimally invasive PD is nowadays only performed in high-volume centers. Laparoscopic PD (LPD) was shown to be feasible and to be associated with lower blood loss and overall complication rates in comparison towith the open approach [24]. The role of robotic-assisted PD (RPD) still needs to be assessed by prospective randomized trials.

Giulianotti et al. [10] reported the first case series of RPD in 2003 for both benign and malignant diseases. In the first experiences, the conventional laparoscopic approach was mainly used for the dissection and preparation, and the robotic assistance was adopted for reconstruction in PD. A fully robotic approach has nevertheless been shown to be feasible [25].

In a meta-analysis from Kamarajah et al. [26], RPD showed lower conversion rates and transfusion rates, and a higher number of lymph nodes were harvested than LPD. Interestingly, RPD was also associated with a shorter length of stay but a higher readmission rate than LPD. 
Table 1. Main publications summarizing the current evidence about robotic liver surgery

\begin{tabular}{lllllll}
\hline Publication & Year & Journal & Type of study & $\begin{array}{l}\text { Patients, } \\
n\end{array}$ & Comment & $\begin{array}{l}\text { Level of } \\
\text { evidence }\end{array}$ \\
\hline Giulianotti et al. [10] & 2003 & Arch Surg & Retrospective & 4 & First report of robotic-assisted liver resections & VI \\
\hline Ziogas et al. [18] & 2021 & Surg Endosc & Meta-analysis & 525 & Most recent published meta-analysis comparing RLS and LLS & IV \\
\hline Aziz et al. [20] & 2021 & J Robot Surg & Retrospective & 11,186 & $\begin{array}{l}\text { Analysis of the nationwide readmission database comparing the IV } \\
\text { outcome of OLS, LLS, and RLS }\end{array}$ \\
\hline Sham et al. [22] & 2016 & J Robot Surg & Retrospective & 71 & Cost analysis of RLS & V \\
\hline
\end{tabular}

RLS, robotic liver surgery; LLS, laparoscopic liver surgery; OLS, open liver surgery.

Table 2. Main publications summarizing the current evidence about robotic pancreatic surgery

\begin{tabular}{|c|c|c|c|c|c|c|}
\hline Publication & Year & Journal & Type of study & $\begin{array}{l}\text { Patients, } \\
n\end{array}$ & Comment & $\begin{array}{l}\text { Level of } \\
\text { evidence }\end{array}$ \\
\hline Giulianotti et al. [10] & 2003 & Arch Surg & Retrospective & 13 & First report of robotic-assisted pancreas resections & $\mathrm{VI}$ \\
\hline Kamarajah et al. [26] & 2020 & Eur J Surg Oncol & Meta-analysis & 3,462 & Most recent published meta-analysis comparing RPD and LPD & IV \\
\hline Kauffmann et al. [34] & 2020 & Updates surgery & Retrospective & 5 & First report of arterial resection during RPD & $\mathrm{VI}$ \\
\hline Di Martino et al. [39] & 2021 & Int J Med Robot & Meta-analysis & 1,187 & Most recent published meta-analysis comparing RDP and LDP & V \\
\hline Lof et al. [37] & 2021 & Br J Surg & Retrospective & 1,151 & $\begin{array}{l}\text { Most recent published multicenter analysis comparing RDP and } \\
\text { LDP }\end{array}$ & IV \\
\hline
\end{tabular}

RPD, robotic pancreaticoduodenectomy; LPD, laparoscopic pancreaticoduodenectomy; RDP, robotic distal pancreatectomy; LDP, laparoscopic distal pancreatectomy.

Table 3. Available and ongoing RCTs comparing RAMIE with either OTE or MIE

\begin{tabular}{llll}
\hline Study name & Type of study & Status & Study design \\
\hline ROBOT trial & RCT & Published (Ann Surg 2019) & Single-center randomized controlled trial comparing OTE and RAMIE \\
REVATE trial & RCT & Ongoing & Multicenter, open-label, randomized controlled trial comparing RAMIE and VATE \\
RAMIE & RCT & Ongoing & $\begin{array}{l}\text { Multicenter prospective randomized, noninferiority phase III clinical trial comparing RAMIE } \\
\text { and MIE }\end{array}$ \\
& & & \\
\hline
\end{tabular}

RCT, randomized controlled trial; OTE, open transthoracic esophagectomy; RAMIE, robotic-assisted minimally invasive esophagectomy; VATE, videoassisted thoracoscopic esophagectomy; MIE, minimally invasive esophagectomy.

Operating time, blood loss, complications (including pancreatic fistula), and mortality showed no differences. However, most of the included studies were single arm studies reporting experiences either on LPD or on RPD. There are only 6 retrospective studies comparing the 2 approaches [26] (see Table 2).

Most of the published studies showed no difference in the rate of postoperative pancreatic fistula (POPF) between RPD and LPD. However, Klompmaker et al. [27] reported in a multicentric study a higher POPF rate in patients receiving a single-row pancreaticojejunostomy during minimally invasive $\mathrm{PD}$, this type of anastomosis being more prevalent in LPD than in RPD. Moreover, Vining et al. [28] reported a higher rate of percutaneous drainages following LPD, despite a similar incidence of POPF in a retrospective cohort study comparing LPD and RPD.

In regard to oncological radicality, RPD showed a lower margin involvement as conventional open $\mathrm{PD}$ in a recently published meta-analysis from Xiang et al. [29]. The comparison with the LPD showed no significant differences [30].

The robotic-assisted approach was also reported to be feasible in challenging resections, including tumors with vascular infiltration [31, 32]. Robotic-assisted vascular resection was shown to have similar postoperative outcomes as OPD, whereas operating time, median estimat- 
ed blood loss, and blood transfusion rate were reported to be higher [33]. A case series of 5 RPD with arterial resection was also recently published [34], no conversion to the open approach was needed, and none of the patients developed severe complications.

\section{Robotic-Assisted Distal Pancreatectomy}

For distal pancreatectomy (DP), the minimally invasive approach had a faster establishment than for PD. Randomized controlled trials are indeed lacking, but a multicentric study comparing minimally invasive (laparoscopic or robotic-assisted) and open DP was started, and results should be available approximately in 2024 [35]. However, already available studies show very positive results for laparoscopic DP (LDP) compared with the conventional open approach [36].

Regarding the robotic-assisted DP (RDP), many comparative studies were published in the last years. A recently published multicentric study from the European Consortium on Minimally Invasive Pancreatic Surgery including 1,551 patients showed RDP to have longer operating time, lower conversion rates, higher spleen preservation rates, longer hospital stay, and lower readmission rate than LDP. No significant differences in regard to mortality and complications (including pancreatic fistula) were reported [37].

In a meta-analysis from 2019, Kamarajah et al. [38] reported similar results, but the reported differences in spleen preservation rates were not statistically significant (see Table 2). RDP seems to be associated with statistically significant higher costs than LDP. In particular, this difference seems to be more remarkable in Asian studies than in Western studies [39].

\section{Robotic-Assisted Esophageal Surgery}

Minimally invasive esophagectomy using laparoscopic and thoracoscopic techniques has been shown to reduce the surgical trauma and postoperative complications, especially pulmonary complications, while showing equivalent long-term survival outcome compared to open esophagectomy [40, 41]. Following the development of robotic operating systems, the esophagus was thought to be the ideal organ for robotic procedures, being in a narrow space (mediastinum) which is technically challenging to reach with conventional laparoscopic instruments. The first reported robotic transhiatal esophagectomy for carcinoma was carried out in 2001 in Chicago, IL, by Horgan et al. [42], followed by the first transthoracic esophagectomy in 2002 in Iowa [43]. In the same year, Melvin et al. [44] reported the first robotic Ivor Lewis procedure.

Robotic-assisted minimally invasive esophagectomy (RAMIE) was compared with conventional open trans- thoracic esophagectomy (OTE) in a randomized controlled trial (ROBOT trial) from van der Sluis et al. [45] showing less blood loss, lower postoperative pain, and less overall complications. The rate of anastomotic leakage was comparable. No differences in oncological outcome were reported. The long-term follow-up of this study showed that overall survival rates and disease-free survival rates are comparable in both groups [46] (see Table 3).

In particular, pulmonary complications and cardiac complications occurred in a significantly lower percentage in the RAMIE group than in the OTE group with $28 \%$ versus $55 \%$ and $22 \%$ versus $47 \%$, respectively. The previously published TIME trial, comparing OTE with laparoscopically and thoracoscopically assisted esophagectomy, showed a low postoperative pneumonia rate of $36 \%$ for the minimally invasive group as well [47]. Further randomized controlled studies comparing RAMIE with minimally invasive esophagectomy (MIE) are still ongoing $[48,49]$ (see Table 3).

In recent meta-analysis, RAMIE showed lower estimated blood loss, lower vocal cord palsy rate, and higher number of harvested lymph nodes than MIE $[50,51]$. Available data show mainly longer operating time for RAMIE than for MIE. A potential reason may be the necessity of repositioning the robotic charts when switching between the abdominal and the thoracic parts [52]. The reported rate of anastomotic leakage for RAMIE has a tendency to be higher than for MIE. The authors postulated that due to the better view with the robotic approach, a more accurate dissection than for the standard thoracoscopic approach is performed, with consequent higher exposure of the cranial end of the divided esophagus [52]. Long-term outcomes were reported to be comparable between RAMIE and MIE in terms of 3-year overall survival [53, 54], 5-year overall survival [55], and median survival time [56].

\section{Conclusion}

Results from recent studies are promising and suggest that RS may be a sufficient alternative to LS in the near future, especially in the challenging fields of hepatic, esophageal, and pancreatic surgery. The higher costs of RS are still a problem and have to be taken into consideration for the future development of the field. The mainly retrospective design of the available studies represents nevertheless the strongest bias of the current evidence. Randomized controlled trials are urgently needed.

\section{Conflict of Interest Statement}

The authors have no conflicts of interest to declare. 


\section{Funding Sources}

No funding was needed for this review.

\section{Author Contributions}

Pasquale Scognamiglio and Björn-Ole Stüben designed the literature research and drafted the manuscript. Asmus Heumann, Jun Li, Jakob R. Izbicki, Daniel Perez, and Matthias Reeh drafted, reviewed, and edited the manuscript.

\section{References}

1 Marino MV, Shabat G, Gulotta G, Komorowski AL. From illusion to reality: a brief history of robotic surgery. Surg Innov. 2018; 25(3):291-6.

2 Hughes-Hallett A, Mayer EK, Marcus HJ, Cundy TP, Pratt PJ, Parston G, et al. Quantifying innovation in surgery. Ann Surg. 2014; 260(2):205-11.

3 Pugin F, Bucher P, Morel P. History of robotic surgery: from $\operatorname{AESOP}(\mathrm{R})$ and ZEUS(R) to da Vinci(R). J Visc Surg. 2011;148(5 Suppl): e3-8.

4 Kim HI, Han SU, Yang HK, Kim YW, Lee HJ, Ryu KW, et al. Multicenter prospective comparative study of robotic versus laparoscopic gastrectomy for gastric adenocarcinoma. Ann Surg. 2016;263(1):103-9.

5 Stoffels B, Glowka TR, von Websky MW, Kalff JC, Vilz TO. [Robot-assisted operations in visceral surgery]. Chirurg. 2020;91(3):1904.

6 Lyman WB, Passeri M, Sastry A, Cochran A, Iannitti DA, Vrochides D, et al. Robotic-assisted versus laparoscopic left pancreatectomy at a high-volume, minimally invasive center. Surg Endosc. 2019;33(9):2991-3000.

7 Barbash GI, Glied SA. New technology and health care costs: the case of robot-assisted surgery. N Engl J Med. 2010;363(8):701-4.

8 Marcus HJ, Hughes-Hallett A, Payne CJ, Cundy TP, Nandi D, Yang GZ, et al. Trends in the diffusion of robotic surgery: a retrospective observational study. Int J Med Robot. 2017;13(4).

9 Stewart CL, Ituarte PHG, Melstrom KA, Warner SG, Melstrom LG, Lai LL, et al. Robotic surgery trends in general surgical oncology from the national inpatient sample. Surg Endosc. 2019;33(8):2591-601.

10 Giulianotti PC, Coratti A, Angelini M, Sbrana F, Cecconi S, Balestracci T, et al. Robotics in general surgery: personal experience in a large community hospital. Arch Surg. 2003;138(7): 777-84.

11 Idrees K, Bartlett DL. Robotic liver surgery. Surg Clin North Am. 2010;90(4):761-74.

12 Choi GH, Choi SH, Kim SH, Hwang HK, Kang CM, Choi JS, et al. Robotic liver resection: technique and results of 30 consecutive procedures. Surg Endosc. 2012;26(8):224758.

13 Giulianotti PC, Sbrana F, Coratti A, Bianco FM, Addeo P, Buchs NC, et al. Totally robotic right hepatectomy: surgical technique and outcomes. Arch Surg. 2011;146(7):844-50.

14 Chen PD, Wu CY, Hu RH, Ho CM, Lee PH, Lai HS, et al. Robotic liver donor right hepatectomy: a pure, minimally invasive approach. Liver Transpl. 2016;22(11):1509-18.

15 Machado MAC, Surjan RC, Makdissi F. Robotic ALPPS. Ann Surg Oncol. 2020;27(4): 1174-9.
16 Schmelzle M, Krenzien F, Schöning W, Pratschke J. [Possibilities and limits of robotic liver surgery: current status 2020]. Chirurg. 2021;92(2):107-14.

17 Broering DC, Elsheikh Y, Alnemary Y, Zidan A, Elsarawy A, Saleh Y, et al. Robotic versus open right lobe donor hepatectomy for adult living donor liver transplantation: a propensity score-matched analysis. Liver Transpl. 2020;26(11):1455-64.

18 Ziogas IA, Giannis D, Esagian SM, Economopoulos KP, Tohme S, Geller DA. Laparoscopic versus robotic major hepatectomy: a systematic review and meta-analysis. Surg Endosc. 2021;35(2):524-35.

19 Qiu J, Chen S, Chengyou D. A systematic review of robotic-assisted liver resection and meta-analysis of robotic versus laparoscopic hepatectomy for hepatic neoplasms. Surg Endosc. 2016;30(3):862-75.

20 Aziz H, Wang JC, Genyk Y, Sheikh MR. Comprehensive analysis of laparoscopic, robotic, and open hepatectomy outcomes using the nationwide readmissions database. J Robotic Surg. 2021. Epub ahead of print.

21 Mehdorn AS, Beckmann JH, Braun F, Becker $\mathrm{T}$, Egberts JH. Usability of indocyanine green in robot-assisted hepatic surgery. J Clin Med. 2021;10(3):456.

22 Sham JG, Richards MK, Seo YD, Pillarisetty VG, Yeung RS, Park JO. Efficacy and cost of robotic hepatectomy: is the robot cost-prohibitive? J Robot Surg. 2016;10(4):307-13.

$23 \mathrm{Xu} \mathrm{Y,} \mathrm{Wang} \mathrm{H,} \mathrm{Ji} \mathrm{W,} \mathrm{Tang} \mathrm{M,} \mathrm{Li} \mathrm{H,} \mathrm{Leng} \mathrm{J,} \mathrm{et}$ al. Robotic radical resection for hilar cholangiocarcinoma: perioperative and long-term outcomes of an initial series. Surg Endosc. 2016;30(7):3060-70.

24 Chen K, Liu XL, Pan Y, Maher H, Wang XF. Expanding laparoscopic pancreaticoduodenectomy to pancreatic-head and periampullary malignancy: major findings based on systematic review and meta-analysis. BMC Gastroenterol. 2018;18(1):102.

25 Giulianotti PC, Mangano A, Bustos RE, Gheza F, Fernandes E, Masrur MA, et al. Operative technique in robotic pancreaticoduodenectomy (RPD) at University of Illinois at Chicago (UIC): 17 steps standardized technique-lessons learned since the first worldwide RPD performed in the year 2001. Surg Endosc. 2018;32(10):4329-36.

26 Kamarajah SK, Bundred J, Marc OS, Jiao LR, Manas D, Abu Hilal M, et al. Robotic versus conventional laparoscopic pancreaticoduodenectomy a systematic review and metaanalysis. Eur J Surg Oncol. 2020;46(1):6-14.
27 Klompmaker S, van Hilst J, Wellner UF, Busch OR, Coratti A, D'Hondt M, et al. Outcomes after minimally-invasive versus open pancreatoduodenectomy: a pan-European propensity score matched study. Ann Surg. 2020;271(2):356-63.

28 Vining CC, Kuchta K, Schuitevoerder D, Paterakos P, Berger Y, Roggin KK, et al. Risk factors for complications in patients undergoing pancreaticoduodenectomy: a NSQIP analysis with propensity score matching. J Surg Oncol. 2020;122(2):183-94.

29 Da Dong X, Felsenreich DM, Gogna S, Rojas A, Zhang E, Dong M, et al. Robotic pancreaticoduodenectomy provides better histopathological outcomes as compared to its open counterpart: a meta-analysis. Sci Rep. 2021;11(1):3774.

30 Nassour I, Choti MA, Porembka MR, Yopp AC, Wang SC, Polanco PM. Robotic-assisted versus laparoscopic pancreaticoduodenectomy: oncological outcomes. Surg Endosc. 2018;32(6):2907-13.

31 AlMasri S, Paniccia A, Zureikat AH. Robotic pancreaticoduodenectomy for a technically challenging pancreatic head cancer. J Gastrointest Surg. 2021;25(5):1359.

32 Beane JD, Zenati M, Hamad A, Hogg ME, Zeh HJ 3rd, Zureikat AH. Robotic pancreatoduodenectomy with vascular resection: outcomes and learning curve. Surgery. 2019;166(1):814.

33 Marino MV, Giovinazzo F, Podda M, Gomez Ruiz M, Gomez Fleitas M, Pisanu A, et al. Robotic-assisted pancreaticoduodenectomy with vascular resection. Description of the surgical technique and analysis of early outcomes. Surg Oncol. 2020;35:344-50.

34 Kauffmann EF, Napoli N, Cacace C, Menonna F, Vistoli F, Amorese G, et al. Resection or repair of large peripancreatic arteries during robotic pancreatectomy. Updates Surg. 2020; 72(1):145-53

35 Probst P, Schuh F, Dörr-Harim C, Sander A, Bruckner T, Klose C, et al. Protocol for a randomised controlled trial to compare postoperative complications between minimally invasive and open DIStal PAnCreaTectomy (DISPACT-2 trial). BMJ Open. 2021;11(2): e047867.

36 Lyu Y, Cheng Y, Wang B, Zhao S, Chen L. Assessment of laparoscopic versus open distal pancreatectomy: a systematic review and meta-analysis. Minim Invasive Ther Allied Technol. 2020 Sep 9:1-9. Epub ahead of print.

37 Lof S, van der Heijde N, Abuawwad M, AlSarireh B, Boggi U, Butturini G, et al. Robotic versus laparoscopic distal pancreatectomy: multicentre analysis. Br J Surg. 2021;108(2): 188-95. 
38 Kamarajah SK, Sutandi N, Robinson SR, French JJ, White SA. Robotic versus conventional laparoscopic distal pancreatic resection: a systematic review and meta-analysis. HPB. 2019;21(9):1107-18.

39 Di Martino M, Caruso R, D’Ovidio A, NunezAlfonsel J, Pinilla FB, Collazo YQ, et al. Robotic vs laparoscopic distal pancreatectomies: a systematic review and meta-analysis on costs and perioperative outcome. Int J Med Robot;2021;17(5):e2295.

40 Shanmugasundaram R, Hopkins R, Neeman T, Beenen E, Fergusson J, Gananadha S. Minimally invasive McKeown's vs open oesophagectomy for cancer: a meta-analysis. Eur J Surg Oncol. 2019;45(6):941-9.

41 Mariette C, Markar SR, Dabakuyo-Yonli TS Meunier B, Pezet D, Collet D, et al. Hybrid minimally invasive esophagectomy for esophageal cancer. N Engl J Med. 2019;380(2):15262.

42 Horgan S, Berger RA, Elli EF, Espat NJ. Robotic-assisted minimally invasive transhiatal esophagectomy. Am Surg. 2003;69(7): 624-6.

43 Kernstine KH, DeArmond DT, Karimi M, Van Natta TL, Campos JH, Campos JC, et al. The robotic, 2-stage, 3-field esophagolymphadenectomy. J Thorac Cardiovasc Surg. 2004; 127(6):1847-9.

44 Melvin WS, Needleman BJ, Krause KR, Schneider C, Wolf RK, Michler RE, et al. Computer-enhanced robotic telesurgery. Initial experience in foregut surgery. Surg Endosc. 2002;16(12):1790-2.
45 van der Sluis PC, van der Horst S, May AM, Schippers C, Brosens LAA, Joore HCA, et al. Robot-assisted minimally invasive thoracolaparoscopic esophagectomy versus open transthoracic esophagectomy for resectable esophageal cancer: a randomized controlled trial. Ann Surg. 2019;269(4):621-30.

46 de Groot EM, van der Horst S, Kingma BF, Goense L, van der Sluis PC, Ruurda JP, et al. Robot-assisted minimally invasive thoracolaparoscopic esophagectomy versus open esophagectomy: long-term follow-up of a randomized clinical trial. Dis Esophagus. 2020;33(Suppl 2):doaa079.

47 Biere SS, van Berge Henegouwen MI, Maas KW, Bonavina L, Rosman C, Garcia JR, et al. Minimally invasive versus open oesophagectomy for patients with oesophageal cancer: a multicentre, open-label, randomised controlled trial. Lancet. 2012;379(9829):1887-92.

48 Chao YK, Li ZG, Wen YW, Kim DJ, Park SY, Chang YL, et al. Robotic-assisted Esophagectomy vs Video-Assisted Thoracoscopic Esophagectomy (REVATE): study protocol for a randomized controlled trial. Trials. 2019; 20(1):346.

49 Yang Y, Zhang X, Li B, Li Z, Sun Y, Mao T, et al. Robot-assisted esophagectomy (RAE) versus conventional minimally invasive esophagectomy (MIE) for resectable esophageal squamous cell carcinoma: protocol for a multicenter prospective randomized controlled trial (RAMIE trial, robot-assisted minimally invasive Esophagectomy). BMC Cancer. 2019;19(1):608.
50 Jin D, Yao L, Yu J, Liu R, Guo T, Yang K, et al. Robotic-assisted minimally invasive esophagectomy versus the conventional minimally invasive one: a meta-analysis and systematic review. Int J Med Robot. 2019;15(3):e1988.

51 Li X-K, Xu Y, Zhou H, Cong Z-Z, Wu W-J, Qiang Y, et al. Does robot-assisted minimally invasive oesophagectomy have superiority over thoraco-laparoscopic minimally invasive oesophagectomy in lymph node dissection? Dis Esophagus. 2021;34(2): doaa050.

52 Zheng C, Li XK, Zhang C, Zhou H, Ji SG, Zhong $\mathrm{JH}$, et al. Comparison of short-term clinical outcomes between robot-assisted minimally invasive esophagectomy and video-assisted minimally invasive esophagectomy: a systematic review and meta-analysis. J Thorac Dis. 2021;13(2):708-19.

53 Yerokun BA, Sun Z, Yang CJ, Gulack BC, Speicher PJ, Adam MA, et al. Minimally invasive versus open esophagectomy for esophageal cancer: a population-based analysis. Ann Thorac Surg. 2016;102(2):416-23.

54 Yang Y, Zhang X, Li B, Hua R, Yang Y, He Y, et al. Short- and mid-term outcomes of robotic versus thoraco-laparoscopic McKeown esophagectomy for squamous cell esophageal cancer: a propensity score-matched study. Dis Esophagus. 2020;33(6):doz080.

55 Park S, Hwang Y, Lee HJ, Park IK, Kim YT, Kang CH. Comparison of robot-assisted esophagectomy and thoracoscopic esophagectomy in esophageal squamous cell carcinoma. J Thorac Dis. 2016;8(10):2853-61.

56 Weksler B, Sullivan JL. Survival after esophagectomy: a propensity-matched study of different surgical approaches. Ann Thorac Surg. 2017;104(4):1138-46. 